\title{
Correlation Between Albumin Level and 28-Days Sepsis Related Mortality
}

\author{
Nugroho H.S. ${ }^{1}$, Mafiana $\mathrm{R}^{2 *}$, Irwanto $\mathrm{FH}^{2}$, Husin Syarif ${ }^{3}$ \\ ${ }^{1}$ Resident of Department of Anesthesiology and Intensive Therapy, Faculty of Medicine Universitas Sriwijaya, \\ Mohammad Hoesin Hospital, Palembang, Indonesia \\ ${ }^{2}$ Consultant of Department of Anesthesiology and Intensive Therapy, Faculty of Medicine Universitas Sriwijaya, \\ Mohammad Hoesin Hospital, Palembang, Indonesia \\ ${ }^{3}$ Department of Anatomy, Faculty of Medicine Universitas Sriwijaya, Palembang, Indonesia
}

\section{*Corresponding author:}

Mafiana R

Consultant of Department of

Anesthesiology and Intensive

Therapy, Faculty of Medicine

Universitas Sriwijaya, Mohammad

Hoesin Hospital, Palembang,

Indonesia

Email:

dr_marfiana@gmail.com

https://doi.org/10.37275/jacr.v1i2.147

\begin{abstract}
Introduction: The mortality rate from sepsis is much greater than that from acute coronary syndrome or stroke. Uncontrolled release of cytokines (abnormalities in the inflammatory response) such as TNF- $\alpha$ and IL-1, IL-6 can reduce serum albumin level, so that the presence of hypoalbuminemia conditions can indicate how the inflammatory reaction occurs in septic patients. Albumin can be a predictor of mortality in septic patients. This study aims to determine the correlation between serum albumin level and the 28 -day mortality of patients with sepsis.
\end{abstract}

Methods: This study is an analytical observational study with a retrospective cohort design. The research was conducted in September 2020 until the completion of data collection at dr. Mohammad Hoesin Hospital Palembang. The sample in this study were all sepsis patients in the intensive care unit who were registered in the Medical Record Installation of dr. Mohammad Hoesin Hospital Palembang from 1 January 2019 to 31 December 2019 met the inclusion and exclusion criteria. After the data was collected, analysis was carried out using the STATA program.

Results: The serum albumin value $\leq$ of $2.6 \mathrm{mg} / \mathrm{dL}$ on the fourth day was significant with the mortality of septic patients. Patients with a serum albumin value $\leq 2.6 \mathrm{mg} / \mathrm{dL}$ had a risk of 1.288 times experiencing death compared to an albumin value $>2.6 \mathrm{mg} / \mathrm{dL}$. Albumin in the fourth day had moderate correlation with sepsis patient mortality $(\mathrm{r}=0.497 ; \mathrm{p}=0.001)$

Conclusion: Albumin serum on the fourth day had a moderate correlation with 28 days sepsis patient mortality

Keywords: Hypoalbuminemia, Mortality, Sepsis. 


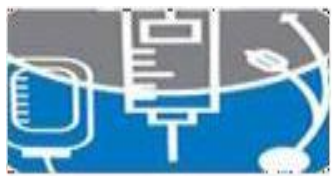

\section{Journal of Anesthesiology \& \\ ClinicalResearch}

\section{Introduction}

Sepsis is one of the causes of morbidity and mortality in the intensive care unit (ICU). The mortality rate from sepsis is much greater than that from acute coronary syndrome or stroke. Mortality can be as high as $30 \%$ in sepsis to $80 \%$ in septic shock. The data were obtained from an epidemiological study of sepsis between 1980 and 2008 in four countries - the United States, Brazil, the United Kingdom, and Australia. From these studies, it is known that the incidence of sepsis in the population ranges from 22 to 240 per 100.000, severe sepsis 13 to 300 per 100.000, and sepsis shock 11 per 100.000. Based on data from an observational study of sepsis and septic shock patients at dr. Cipto Mangunkusumo in Jakarta in 2012 2013, the mortality rate in sepsis and septic shock was around 61\%. In 2017, data obtained at the General Intensive Care Unit (GICU) of dr. Mohammad Hoesin Palembang, the incidence of sepsis was $30.1 \%$ and the 28 -day mortality rate was $46.8 \%$. $^{1}$

The diagnosis of sepsis is to use SOFA and can see the mortality of septic patients, but an accurate and simple measurement tool is needed in predicting the outcome of septic patients. Referring to the results of the latest guidelines, research is rapidly developing that focuses on predicting the outcome of sepsis patients. The theory is developing that acute-phase proteins are the best markers in the pathophysiology of sepsis. $^{2-6}$

The acute phase of inflammation occurs in the first 12-48 hours. This is characterized by the release of inflammatory mediators that trigger inflammation. As a result of the acute phase, hepatocytes have changed the synthesis of several proteins. Inflammation reduces levels of some proteins such as albumin, which are called negative acute phase proteins (because their levels decrease with the inflammatory process). Albumin values tend to fall in the presence of an active-phase reaction such as sepsis and trauma, with a mean decrease ranging from 10-15 g / L in the first week. There are several causes for the occurrence of hypoalbuminemia in septic patients, namely, decreased albumin synthesis in the liver, reduced intake of amino acids, increased fluid transfer to the interstitial (plasma leakage), and increased tissue catabolism. ${ }^{7,8}$ The peak of the decrease in albumin levels occurs at 2-4 days post-inflammation and will decrease along with the resolution of the inflammatory process on days 4 to 7. So, it is ideal to lookat acute phase protein levels as a diagnostic tool for the sepsis process.

In a previous study by Mei Yin et al. in 2016, 116 patients were included in the study, the overall 28day mortality was $26.7 \%$. Compared with the survivor group, non-survivor patients had lower serum albumin values. The ROC curve data showed that albumin level was a strong predictor of 28-day 


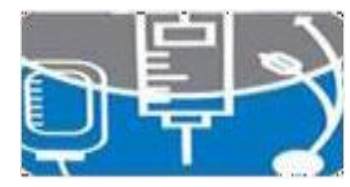

\section{Journal of Anesthesiology \& \\ Clinical Research}

mortality, with the optimal cut-off value being $2.92 \mathrm{~g} / \mathrm{dl}$. Through multivariate regression analysis, low serum albumin levels $(<2.92 \mathrm{~g} / \mathrm{dl})$ were identified as an independent risk factor for mortality. Patients with lower serum albumin had a lower 28-day survival rate than patients with serum albumin $>2.92 \mathrm{~g} / \mathrm{dl} .{ }^{9}$ Another study found albumin levels $<2.6 \mathrm{~g} / \mathrm{dl}$ were associated with the 30 -day mortality of septic patients. 12

Based on the theory that uncontrolled release of cytokines (abnormalities in the inflammatory response) such as TNF- $\alpha$ and IL-1, IL-6 can decrease serum albumin values by modulating the albumin synthesis gene in the liver, albumin can be a predictor of mortality in septic patients. Acute inflammatory reaction peaks on days two to four, being the point of greatest decline in albumin value. The presence of a hypoalbumin condition indicates how the inflammatory reaction occurs in patients with sepsis. Albumin has a function as a major antioxidant in the body. Albumin is a protective factor against an inflammatory response. The low albumin value results in the protective function being not optimal. The patient's output was getting worse. Thus, the albumin value can be used as an indicator of inflammation, capillary leakage, and damage due to oxidative stress in sepsis, all of which facilitate the prognosis of septic patients. ${ }^{4}$ This study aimed to assess the correlation between serum albumin value and 28-day mortalityof septic patients in the ICU RSUP Dr. Mohammad Hoesin Palembang.

\section{Methods}

This study is an analytical observational study with a retrospective cohort design that aims to determine the correlation between serum albumin value and the 28-day mortality of septic patients. This research will be carried out from September 2020 to March 2021. The research was carried out after the approval of the Ethics Committee for Health Research of Mohammad Hoesin General Hospital and the Faculty of Medicine of Sriwijaya University (No. 86 / kepkrsmh / 2020).

All sepsis patients in the intensive care unit who are registered in the Medical Record Installation of Dr. Mohammad Hoesin Palembang from 1 January 2019 to 31 December 2019 who met the inclusion criteria will be the study sample. The inclusion criteria included patients aged 18-65 years with a diagnosis of sepsis. Patients with incomplete medical records are treated in the ICU Dr. Mohammad Hoesin Palembang for less than 24 hours, re-admission to the intensive care unit within the same treatment period, and unable to follow up were excluded from the study.

The sample in this study were all sepsis patients in the intensive care unit who were registered in 


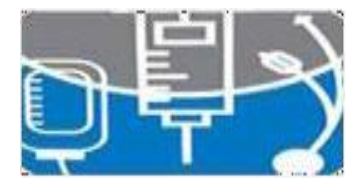

\section{Journal of Anesthesiology \& \\ Clinical Research}

the Medical Record Installation of Dr. Mohammad Hoesin Palembang from 1 January 2019 to 31December 2019 who met the inclusion and exclusion criteria. The minimum sample size needed in this study was 56 sepsis patients. Based on the results of the calculation of the minimum sample size, 51 sepsis patients were obtained, which was added $10 \%$ for the drop-out criteria. The sampling technique in this study was taken using the consecutive sampling technique, where the research sample was taken based on inclusion criteria.

This study consisted of 3 variables: the independent variable (albumin level and SOFA score), the dependent variable (28 days mortality of septic patients), confounding variables (BMI, morbid disease). The albumin level will be divided into $2.6 \mathrm{mg} / \mathrm{dl}$ based on the previous cut-off point.

This research data processing method using software, namely the Stata program. The research data analysis was carried out descriptively and analytically. Descriptive analysis was carried out to determine the amount and percentage for variable data that had a categorical scale (nominal) of each research variable (gender and mortality), while variables with a numerical scale statistical measures were presented in the form of mean \pm standard deviation, median. (minimum-maximum).

The Spearman correlation statistical test was conducted to determine the correlation between the albumin variable and mortality. The ROC statistical test was performed to determine the predictive value of mortality within 28 days from albumin levels and SOFA scores.

\section{Results}

In this study, 59 subjects met the inclusion and exclusion criteria. In the general characteristics of the age of the study subjects on sepsis mortality, it was found that age $>65$ years had the highest mortality rate, which was 3 out of 3 patients, while only six patients aged 18-40 years died. Gender of subjects to sepsis mortality found that as many as $54.5 \%$ of subjects were male and $46.2 \%$ of subjects were female in the living group, while there were as many as $45.5 \%$ male subjects and $53.8 \%$ female subjects in the group who died. From the number of comorbid subjects to sepsis mortality, it was found that the majority of the study samples had no comorbid. The proportion of patients who have comorbidity tends to be more likely to die than the proportion of patients who do not die in which patients with thyroidand asthma have a mortality rate of up to $100 \%$.

In the general characteristics of the type of disease subject to sepsis mortality, it was found that patients with respiratory infections had the highest proportion of deaths $(60.7 \%)$ compared to other types 


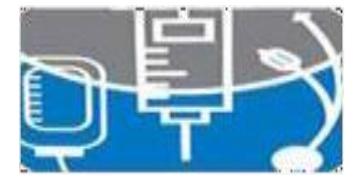

\section{Journal of Anesthesiology \& \\ Clinical Research}

of diseases. Patients who came from the ICU emergency department (IGD) had the highest mortality rate, namely 63.6\%. Patients with high lactate levels, high SOFA scores, and low albumin levels tended to have higher mortality rates.

Table 1. General characteristics

\begin{tabular}{|c|c|c|c|c|}
\hline \multirow{3}{*}{ Variables } & \multicolumn{4}{|c|}{ Mortality } \\
\hline & \multicolumn{2}{|c|}{ Survive $(n=30)$} & \multicolumn{2}{|c|}{ Non-Survive $(n=29)$} \\
\hline & $\mathrm{N}$ & $\%$ & $\mathrm{~N}$ & $\%$ \\
\hline \multicolumn{5}{|l|}{ Age } \\
\hline $18-40$ years old & 7 & 53.8 & 6 & 46.2 \\
\hline $41-64$ years old & 23 & 53.5 & 20 & 46.5 \\
\hline$\geq 65$ years old & 0 & 0 & 3 & 100 \\
\hline \multicolumn{5}{|l|}{ Gender } \\
\hline Male & 18 & 54.5 & 15 & 45.5 \\
\hline Female & 12 & 46.2 & 14 & 53.8 \\
\hline \multicolumn{5}{|l|}{ Comorbidity } \\
\hline Asthma & 0 & 0 & 1 & 100 \\
\hline Diabetes Mellitus & 4 & 80 & 1 & 20 \\
\hline Hypertension & 2 & 66.7 & 1 & 33.3 \\
\hline Tuberculosis & 1 & 25 & 3 & 75 \\
\hline Thyroid & 0 & 0 & 2 & 100 \\
\hline None & 23 & 52.3 & 21 & 47.7 \\
\hline \multicolumn{5}{|l|}{ Infection Source } \\
\hline Gastrointestinal & 10 & 50 & 10 & 50 \\
\hline Respiratory & 11 & 39.3 & 17 & 60.7 \\
\hline Infeksi Lainnya & 9 & 81.8 & 2 & 18.2 \\
\hline \multicolumn{5}{|l|}{ Admission } \\
\hline GICU & 18 & 58.1 & 13 & 41.9 \\
\hline ICU Emergency & 8 & 36.4 & 14 & 63.6 \\
\hline $\mathrm{P} 1$ & 4 & 66.7 & 2 & 33.3 \\
\hline $\begin{array}{l}\text { Lactate. } \\
\text { mean + SD }\end{array}$ & $1.628 \pm 0.814$ & & $2.589 \pm$ & \\
\hline $\begin{array}{l}\text { SOFA Score, } \\
\text { mean }+ \text { SD }\end{array}$ & $5.9 \pm 2.39$ & & $9.10 \pm 2$ & \\
\hline $\begin{array}{l}\text { Albumin inisial, } \\
\text { mean } \pm \text { SD }\end{array}$ & $2.81 \pm 0.09$ & & $2.57 \pm($ & \\
\hline
\end{tabular}

Sepsis patients who non-survived had lower mean scores than patients who survived both the first day (2.81 versus 2.57 ) and the fourth day (3.13 versus 2.53$)$. T-test analysis was carried out and it was found that there was a significant difference in values between the albumin values on the first and fourth days in the living and dead groups $(\mathrm{p}<0.05)$.

The serum albumin level measurement on the fourth day had a significant relationship with the 28- 
day mortality of septic patients $(\mathrm{p}=0.009)$, while the albumin measurement on the first day had no significant relationship with the 28 -day mortality in septic patients $(\mathrm{p}=0.782)$. Patients with an albumin level $<2.6 \mathrm{mg} / \mathrm{dL}$ had a 1.288 times greater risk of dying $(\mathrm{HR}=1.288$; $95 \%$ CI $1.288-5.958)$.

Table 2. Albumin differences in survived and non-survived patients

\begin{tabular}{lccc}
\hline \multirow{2}{*}{ Albumin } & \multicolumn{2}{c}{ Mortality } & \multirow{P}{*}{ Non-Survive (n=29) } \\
\cline { 2 - 3 } & Survived (n=30) & Non & \\
\hline First day, mean \pm SD & $2.81 \pm 0.09$ & $2.57 \pm 0.06$ & 0.036 \\
Fourth day, mean \pm SD & $3.13 \pm 0.09$ & $2.53 \pm 0.07$ & 0.001 \\
\hline
\end{tabular}

Notes: Analyzed using Independent T-Test, $\mathrm{p}<0.05=$ significant

Table 3. Albumin and mortality relationship

\begin{tabular}{|c|c|c|c|c|c|c|c|}
\hline \multirow{3}{*}{ Albumin } & \multicolumn{4}{|c|}{ Mortality } & \multirow{3}{*}{$p$} & \multirow{3}{*}{ HR } & \multirow{3}{*}{$95 \% \mathrm{CI}$} \\
\hline & \multicolumn{2}{|c|}{$\begin{array}{c}\text { Survive } \\
(n=30)\end{array}$} & \multicolumn{2}{|c|}{$\begin{array}{c}\text { Non-survive } \\
(n=29)\end{array}$} & & & \\
\hline & $\mathbf{n}$ & $\%$ & $\mathbf{n}$ & $\%$ & & & \\
\hline \multicolumn{8}{|l|}{ First Day } \\
\hline$\leq 2.6 \mathrm{~g} / \mathrm{dl}$ & 14 & 48.3 & 15 & 51.7 & 0.782 & 1.10 & $0.053-2.296$ \\
\hline$>2.6 \mathrm{~g} / \mathrm{dl}$ & 16 & 53.3 & 14 & 46.7 & & & \\
\hline \multicolumn{8}{|l|}{ Fourth Day } \\
\hline$\leq 2.6 \mathrm{~g} / \mathrm{dl}$ & 5 & 20.8 & 19 & 79.2 & 0.009 & 1.288 & $1.288-5.958$ \\
\hline$>2.6 \mathrm{~g} / \mathrm{dl}$ & 25 & 71.4 & 10 & 28.6 & & & \\
\hline
\end{tabular}

Notes: Analyzed with Chi-Squaret Test, $\mathrm{p}<0.05=$ significant; HR $=$ hazard ratio; 95\% CI $=95 \%$ Confidence Interval

The SOFA score had a mean value of $5.9 \pm 0.43$ in the surviving group and $9.10 \pm 0.47$ in the nonsurvive group. A normality test was carried out using the Kolmogorov Smirnov test, then the T analysis test was carried out and it was found that SOFA had a difference in values between the living and dead groups with a value of $p=0,000$, this was because the SOFA value in the non-survived group was higher. 


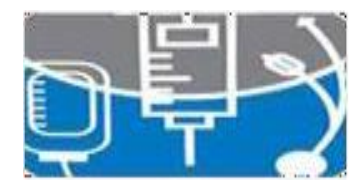

\section{Journal of Anesthesiology \& \\ ClinicalResearch}

Table 4. Sofa score characteristics

\begin{tabular}{|c|c|c|c|}
\hline \multirow{2}{*}{ Variable } & \multicolumn{2}{|c|}{ Mortality } & \multirow{2}{*}{$p$} \\
\hline & Survive $(n=30)$ & Non-survive $(n=29)$ & \\
\hline SOFA score, mean \pm SD & $5.9 \pm 0.43$ & $9.10 \pm 0.47$ & 0.001 \\
\hline
\end{tabular}

Notes: Analyzed with Independent T-Test, $\mathrm{p}<0.05=$ significant

A correlation test was performed using Spearman and it was found that the albumin value on the first day did not have a significant correlation with sepsis mortality $(r=0.05 ; \mathrm{p}=0.703)$, while the albumin value on the fourth day had a moderate correlation with septic mortality $(r=0.4972)$, and the error rate for being able to accept the condition of the albumin value on the mortality of sepsis is moderate at $<5 \%$ ( $\mathrm{p}=$ $0.001)$.

Tabel 5. Albumin and mortality correlation

\begin{tabular}{ccc}
\hline \multirow{2}{*}{ Variable } & \multicolumn{2}{c}{ Mortality } \\
\cline { 2 - 3 } & $\mathbf{r}$ & $p$ \\
\hline Albumin First Day & 0.0506 & 0.703 \\
Albumin Fourth Days & 0.4972 & 0.001
\end{tabular}

Notes: Correlation test using Spearman Test, albumin fourth days signifikan $(\mathrm{p}<0.05)$

r: Coefficient correlation, with interpretation

$0-0.10$ very low correlation

$0.10-0.39$ low correlation

$0.40-0.69$ moderate correlation

$0.70-0.89$ strong correlation

$0.90-1$ very strong correlation

Source: Anesthesia\&analgesia126(5):1763-1768, May 2018

The results of the analysis model found that patients with sepsis with albumin levels on day 4 of 

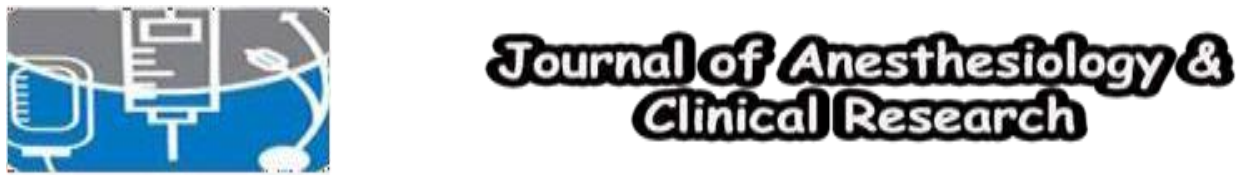

$2.6 \mathrm{mg} / \mathrm{dL}$ or less had a risk of 2.267 times to experience death within 28 days after considering the SOFA score variable. The results of the analysis of confounding variables can be seen in the following table:

Table 6. Hazard ratio in albumin and SOFA Score

\begin{tabular}{lcccc}
\hline \multirow{2}{*}{ Variable } & HR & \multicolumn{2}{c}{ 95\% Confidence } \\
& & Interval & \multirow{2}{*}{$\boldsymbol{p}$} \\
\cline { 3 - 4 } & & Lower & Upper & \\
\hline Albumin (Day-four) & 6.959 & 0.93 & 51.7 & 0.05 \\
SOFA Score & 2.267 & 1.04 & 4.89 & 0.037 \\
\hline
\end{tabular}

\section{Discussion}

This study found that age $>65$ years had the highest mortality rate (100\%) while 18-40 had the lowest mortality rate, namely 6 patients died (46 2\%). A study by Martin in 2019 found that the overall hospital mortality due to sepsis was $48.8 \%(\mathrm{n}=727)$ and was significantly higher in elderly patients 65 - 79 years compared to elderly patients $>80$ years $(54,2 \%$ versus $47.4 \% ; \mathrm{p}=0.02)$. The 28 -day mortality was $39.6 \%$ $(\mathrm{n}=590)$ and was significantly higher in elderly patients 65-79 years compared to elderly patients $>80$ years $(46.8 \%$ versus $37.8 \%$; $\mathrm{p}=0.005) .{ }^{11}$ Older sepsis patients often die early during their hospital stay. The innate immune response and adaptive immune response decreased with aging which largely contributes to the incidence of infection. Decreased adaptive immune response leads to decreased immunity in elderly patients. In the adaptive immune system, the number of B cells and the generation of $\mathrm{T}$ cells decreases with aging causing a reduced system response to new pathogens

As many as $45.5 \%$ of the subjects were male and $53.8 \%$ of the subjects were female in the group who died. This result is in accordance with Anthony's research which found that mortality in the hospital was higher in women than men $(35 \%$ compared to $33 \%, \mathrm{p}=0.006) .{ }^{13}$ In contrast to the results of NosheenNasir's study in 2015 found that from 54\% men and 46\% women, men had higher mortality ( $\mathrm{p}=0.048, \mathrm{RR} 1.73$ ) and plasma IL-6 levels $(\mathrm{p}=0.040)$ than women. Mean plasma IL-6 levels were significantly ( $\mathrm{p}$ $<0.01)$ higher in non-survived patients than in those who recovered. Nosheen describes the possibility that men in his study population had a high risk of mortality because male subjects had higher levels of IL-6 in their study and other studies have shown that high IL-6 is associated with higher mortality. ${ }^{11}$ 


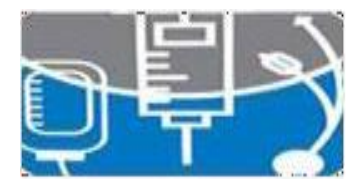

\section{Journal of Anesthesiology \& \\ Clinical Research}

The majority of the study sample had no comorbid. The proportion of patients who have comorbidity tends to be more likely to die than the proportion of patients who do not die in which patients with thyroid and asthma have a mortality rate of up to $100 \%$. Whiles' 2016 study of 7071 cases of sepsis / severe septic shock, the most common documented comorbidity was hypertension (56.2\%) and the least common was gastric ulcer disease $(0.04 \%)$. The patient mortality without comorbidity was $2.4 \%$. Metastatic cancer was associated with the highest mortality (17.4\%). Between patients with a Charlson's comorbidity score of 0 and 1-3, no significant difference was seen in mortality. However, among patients with $>4$ comorbidities, the likelihood of death increased with each increase in the number of comorbidities ( 4 ( $O R=3.48,95 \%$ CI: $1.09-11.1)$ or $>5(\mathrm{OR}=3.5,95 \%$ CI: $1.10-11.0) .{ }^{13}$ The more comorbidity of the patient, the patient will have a more severe degree of disease. This results in the measurement of patient outcomes including mortality. comorbidity will reduce mortality. ${ }^{14}$

In the group of treatment origin from GICU, ICU IGD and P1 did not have a large enough difference. Patients who came from the ICU ER had the highest mortality rate of 63.6\%. This is in contrast to previous studies which stated that septic patients who entered the ICU from the wards experienced higher mortality than patients who came from the ER. ${ }^{15}$ This difference could be caused by more complete hospital infrastructure in the GICU room compared to the ICU emergency so that patient mortality in the GICU.

The incidence of sepsis is higher in patients with chronic medical conditions that impair immune function, especially in patients with cancer, acquired immunodeficiency syndrome (AIDS), diabetes, and chronic obstructive pulmonary disease (COPD), in patients taking immunosuppressive drugs, and in patients on hemodialysis. For example, the incidence of sepsis was approximately 40 times higher i $n$ patients undergoing hemodialysis compared to patients who did not undergo hemodialysis. Nationally, the US hospital discharge records estimate the incidence rate of sepsis is 755 per 100.000 patients with COPD. Patients with diabetes have a 2.5 times higher risk of hospitalization for sepsis than patients without diabetes ${ }^{16}$.

In this study, it was found that the group of patients who died had higher serum lactate levels than the survivors $(2.589 \pm 2.246$ versus $1.628 \pm 0.814)$. Serum lactate increases due to accelerated glycolysis and tissue hypoxia and can be a predictor of mortality in patients. Research by Villar et al found that lactate can predict both short- and long-term mortality in septic patients. Patients with high lactate levels have a lower ability to adapt to physiological stressors and have a longer recovery time. ${ }^{17}$ 


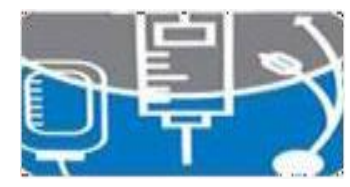

\section{Journal of Anesthestology \&
Clinical Research}

There were $30(50.85 \%)$ sepsis patients who were alive and as many as $29(49.15 \%)$ sepsis patients who died. This shows a high sepsis mortality rate. Sepsis is one of the causes of morbidity and mortality in the ICU. The death rate from sepsis is much greater than that of acute coronary syndrome or stroke. Mortality can be as high as $30 \%$ in sepsis to $80 \%$ in septic shock. The data were obtained from an epidemiological study of sepsis between 1980 and 2008 in four countries - the United States, Brazil, the United Kingdom, and Australia. From these studies, it is known that the incidence of sepsis in the population ranges from 22 to 240 per 100,000, severe sepsis 13 to 300 per 100,000, and sepsis shock 11 per 100,000. Based on data from an observational study of sepsis and septic shock patients at dr. Cipto Mangunkusumo in Jakarta in 2012 - 2013, the mortality rate in sepsis and septic shock was around 61\%. In 2017, data obtained at the General Intensive Care Unit (GICU) of dr. Mohammad Hoesin Palembang, the incidence of sepsis was $30.1 \%$ and the 28 -day mortality rate reached $46.8 \%{ }^{1}$ In this study, it was found that many patients died due to sepsis, namely $49.15 \%$.

There was a significant difference in the mean value of albumin levels in the two groups where there were more patients with lower albumin levels in the group who died than in patients who survived the first day (2.81 versus 2.57 ) and the fourth day (3.13 compared 2.53). In this study, the albumin cut-off point was used based on previous studies where albumin was a prognostic factor associated with 30 -day mortality as follows: albumin level $<2.6 \mathrm{~g} / \mathrm{dl}$ (first quartile of the entire population). The albumin value on the fourth day had a significant correlation with moderate correlation strength on sepsis mortality $(r=0.4972 ; p=$ 0.001). Albumin levels can potentially be considered part of the prognosis and potential future interventions. ${ }^{10}$ Albumin levels reflect the patient's previous nutritional status, organic function, or physical activity. However, the underlying inflammatory status via increased interleukin-1 or tumor necrosis factor induces a decrease in hepatic albumin production which is partly responsible for the hypoalbuminemia seen in the early stages of sepsis. In addition, the hypothesis for the impact of albumin on the prognosis of infection is the fact that antimicrobial pharmacokinetics can be altered by hypoalbuminemia (i.e., high protein-bound free plasma level antibiotics can be significantly reduced due to increased elimination) which impairs antimicrobial levels in patients with low albumin. ${ }^{18-21}$

Based on Table 5, after a multivariate analysis between albumin and SOFA scores, it was found that the albumin variable on day 4 was statistically significant with a moderate correlation value ( $\mathrm{p}$-value $=$ $0.001 ; r=0.492$ ). In Table 6 , after analyzing the hazard ratio, the HR value of serum albumin on day 4 was 2.267 (95\% CI 1.04 - 4.89), while on day 1 there was no significant relationship. The albumin level 


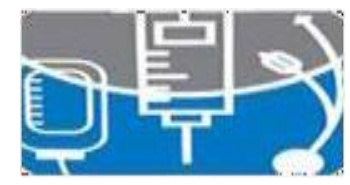

\section{Journal of Anesthesiology \& \\ Clinical Research}

on the first day tends not to change or decrease. Research from Takegawa et al found that serum albumin began to decrease on the fourth day onwards. Serum albumin is a major contributor to osmotic pressure. The decrease in serum albumin on the fourth day was caused by damage to the target liver organ in severe and prolonged sepsis resulting in a decrease in severe osmotic pressure, which resulted in changes in vascular permeability resulting in higher mortality than patients who did not experience a decrease in serum albumin levels. $^{22}$

Theoretically, the association between hypoalbuminemia and mortality in patients with sepsis may have several explanations. The first is the uncontrolled release of cytokines (abnormalities in the inflammatory response). Cytokines such as TNF- $\alpha$ and IL-1 can reduce serum albumin levels by modulating the albumin synthesis gene. Second, redistribution of intravascular albumin in critical illness can lead to an increased interstitial transfer of albumin after sepsis, known as capillary leak syndrome, which significantly increases the risk of death. Third, ischemia, hypoxia, and oxidative damage often follow severe infection, and albumin is the main extracellular plasma target protein for oxidative stress. Among the various proteins found in plasma, albumin represents the dominant antioxidant. Although the antioxidant effect of albumin may be of biologically relevant protection, the prolonged inflammatory process in sepsis can increase albumin catabolism, because capillary repair takes a long time. If we deduce from this theory, albumin value can be used as an indicator of inflammation and damage due to oxidative stress in sepsis, all of which facilitate the prognosis of septic patients. ${ }^{9}$

In table 4 , it is found that the SOFA scores of the two groups were significantly different $(\mathrm{p}=0.000)$ with a mean value of $5.9 \pm 0.43$ in the living group and $9.10 \pm 0.47$ in the dead group. The SOFA score is a score to measure organ function. The higher the SOFA score, the heavier the organ damage occurs. The SOFA score could predict the mortality of septic patients. ${ }^{17}$ The mean SOFA score and capillary lactate level of the living patients were generally smaller than the group who died, namely 4.89 \pm 2.06 compared to $7.64 \pm 2.67$ ( $\mathrm{p}<0,05) ; 3.28 \pm 1.39$ versus $3.60 \pm 1.43$ (p 0.116$).{ }^{23}$ This study used the cut-off point of the SOFA score from Made's study which found that the best cut-off value of the SOFA score for mortality was $\geq 5.5$ (area under the curve / AUC 0.788 , sensitivity $74.2 \%$ and specificity $62.2 \%$, positive predictive value / PPV 62.2\%, and negative predictive value / NPV 74.2\%). The log-rank test for the Kaplan-Meier curve was statistically significant $(\mathrm{p}<0.05)$. Cox multivariate regression analysis showed that the SOFA score with a cut-off $\geq$ of 5.5 can be used as a predictor of mortality in septic patients with a hazard ratio of $2.475(\mathrm{p}<0.05) .{ }^{24}$ In line with the above study, based on Table 6 , 


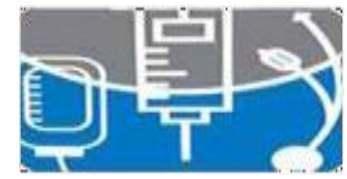

\section{Journal of Anesthesiology \& \\ Clinical Research}

this study also found that, the significant difference between the SOFA levels in the group of living and dying patients with a value of $p=0.037$, this is because the SOFA value in the group who died was higher, indicating more extensive organ damage.

\section{Conclusions}

The serum albumin levels of patients who died on the first and fourth days were lower than those who survived $(\mathrm{p}=0.036$ and $\mathrm{p}=0.001)$. The serum albumin value $\leq$ of $2.6 \mathrm{mg} / \mathrm{dL}$ on the fourth day was significant with the mortality of septic patients. Patients with a serum albumin value $\leq 2.6 \mathrm{mg} / \mathrm{dL}$ on the fourth day had a risk of death 1.288 times compared to albumin values $>2.6 \mathrm{mg} / \mathrm{dL}(\mathrm{p}=0.009)$. The fourthday serum albumin value had a moderate correlation with 28 days of patient mortality. sepsis in ICU ( $\mathrm{r}=$ $0.497 ; \mathrm{p}=0.001)$

\section{References}

1. Arifin, Trilaksmi A, Semedi BP, Wisudarti CF, Pangalila F, Razi F, et al. Penatalaksanaan sepsis dan syok sepsis (OptimalisasiFASTHUGSBID). Jakarta: PERDICI; 2017, hal 1-13

2. Abe T, Ogura H, Shiraishi A, Kushimoto S, Saitoh D, Fujishima S, et al. Characteristics, management, and in-hospital mortality among patients with severe sepsis in intensive care units in Japan: the FORECAST study. Crit Care. 2018;22(1):1-21.

3. Lambden S, Laterre P, Levy M, Francois B. The SOFA score development, utility and challenges of accurate assessment in clinical trials. Crit Care. 2019;22(374):1-9.

4. Sharma Z, Bale C, Kakrani A, Dabadghao V. Sequential organ failure assessment score as prognostic marker in critically ill patients in a tertiary care intensive care unit. Int. J Public Health. 2013;3(3):155.

5. Vincent J, Moreno R, Takala J, Willatts S, De Mendonça A, Bruining H, et al. The SOFA (Sepsisrelated Organ Failure Assessment) score to describe organ dysfunction/failure. Intensive Care Med. 1996;22(7):707-10

6. Safari S, Shojaee M, Rahmati F, Barartloo A, Hahshemi B, Forouzanfar M, et al. Accuracy of SOFA score in prediction of 30-day outcome of critically ill patients. Turk J Emerg Med. 2016;16(4):146-50. 


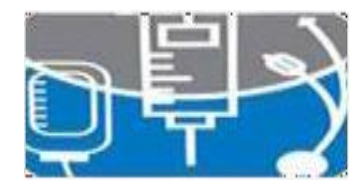

\section{Journal of Anesthestology \&
Clinical Research}

7. Seo M, Choa M, You J, Lee H, Hong J, Park Y, et al. Hypoalbuminemia, low base excess values, and tachypnea predict 28-day mortality in severe sepsis and septic shock patients in the emergency department. Yonsei Med J. 2016;57(6):1361.

8. Scmidt de Oliveira-Netto A, Morello L, Dalla-Costa L, Petterle R, Fontana R, Conte D, et al. Procalcitonin, C-Reactive Protein, albumin, and blood cultures as early markers of sepsis diagnosis or predictors of outcome: A prospective analysis. Clin Pathol.2019;12:1-7

9. Yin M, Si, L, Qin W, Li C, Zhang J, Yang H et al. Predictive value of serum albumin level for the prognosis of severe sepsis without exogenous human albumin administration: A prospective cohort study: J Intensive Care Med. 2016; 33(12):687-94

10. Arnau-Barrés I, Güerri-Fernández R, Luque S, Sorli L, Vázquez O, Miralles R. Serum albumin is a strong predictor of sepsis outcome in elderly patients. Eur J Clin Microbiol Infect Dis. 2019;38(4):74346.

11. Martin IL, Gula MC, Valleococcia MS, Suarez D, Ibarz M, Irazabal M, et al. Risk factors for mortality in elderly and very elderly critically ill patients with sepsis: a prospective, observational, multicenter cohort study. Ann Intensive Care. 2019;9(26):1-9.

12. Starr ME, Saito H. Sepsis in old age: review of human and animal studies. Aging Dis. 2014;5(2):12636.

13. Whiles B, Deis A, Miller P, Simpson S. Comorbid conditions predict outcomes in patients with severe sepsis. Chest Journal. 2016;149(4):1.

14. Yang, Y, Yang KS, Hsann YM, Lim V, Ong BC. The effect of comorbidity and age on hospital mortality and length of stay in patients with sepsis. Journal of Critical Care.2010;25:398-405.

15. Motzkus CA, Chrysanthopoulou SA, Luckmann R, Rincon TA, Lapane KL, Lilly CM. ICU admission source as a predictor of mortality for patients with sepsis. J Intensive Care Med. 2018;33(9):510-6.

16. Dagher GA, Harmouche E, Jabbour E, Bachir R, Zebian D, Chebl RB. Sepsis in hemodialysis patients. BMC Emrg Med. 2015;15(30):1-6

17. Villar J, Short JH, Lighthall G. Lactate predicts both short and long terms mortality in patients with and without sepsis. Infect Dis.2019;12:1-6

18. Jain S, Gautam V, Naseem S. Acute-phase proteins: as diagnostic tool. J Pharm Bioallied Sci. 


\section{Sournal of Anesthesiofogy 8 \\ Clinical Research}

2011;3(1):118.

19. Juneja D. Severe sepsis and septic shock in the elderly: An overview. World Journal of Critical Care Medicine. 2012;1(1):23.

20. Churpek M, Snyder A, Han X, Sokol S, Pettit N, Howell M, et al. Quick sepsis-related organ failure assessment, systemic inflammatory response syndrome, and early warning scores for detecting clinical deterioration in infected patients outside the intensive care unit. Am J Respir Crit. 2017;195(7):90611.

21. Akirov A, Masri-Iraqi H, Atamna A, Shimon I. Corrigendum to low albumin levels are associated with mortality risk in hospitalized patients. Am J Med. 2017;130(12):1-27.

22. Takegawa R, Kabata D, Shimizu K, Hisano S, Ogura H, Shintani A, et al. Serum albumin as a risk factor for death in patients with prolonged sepsis: an observational study. Journal of Critical Care. 2019:139-44.

23. Jain A, Palta S, Saroa R, Palta A, Sama S, Gombar S. Sequential organ failure assessment scoring and prediction of patient's outcome in intensive care unit of a tertiary care hospital. 2016;32(3):364368.

24. Taofik S, Senapathi TGA, Wiryana M. Perbandingan validitas sistem skoring APACHE II, SOFA dan customized sequential organ failure assessment (CSOFA) untuk memperkirakan mortalitas pasien non-bedah yang dirawat di ruang perawatan intensif. JAI. 2015;7(2):102-13. 